九州大学学術情報リポジトリ

Kyushu University Institutional Repository

Contrastive or Interconvertible Relationships between Forage and Ruminant Growth Analysis Equations - A Simple Description using a Symmetry-like Characteristic -

Shimojo, Masataka

Laboratory of Animal Feed Science, Faculty of Agriculture, Kyushu University

Bungo, Takashi

Shikoku National Agricultural Experiment Station

Imura, Yoshimi

Laboratory of Animal Feed Science, Faculty of Agriculture, Kyushu University

Tobisa, Manabu

Laboratory of Animal Feed Science, Faculty of Agriculture, Kyushu University

他

https://doi.org/10.5109/24329

出版情報 : 九州大学大学院農学研究院紀要. 44 (3/4)，pp. 279-285，2000-02. Kyushu University バージョン：

権利関係： 


\title{
Contrastive or Interconvertible Relationships between Forage and Ruminant Growth Analysis Equations - A Simple Description using a Symmetry-like Characteristic -
}

\author{
Masataka Shimojo, Takashi Bungo*, Yoshimi Imura, Manabu Tobisa, \\ Mitsuhiro Furuse, Yasuhisa Masuda, Yasukatsu Yano, Yutaka Nakano**, \\ Tao Shao, Muhammad Yunus and Ichiro Goto***
}

Laboratory of Animal Feed Science, Faculty of Agriculturc, Kyushu l'niversity, Fukuoka 812-8581, Japan

(Recived October 29, 1999 and accepted November 5, 1999)

\begin{abstract}
The present study suggested (1) a symmetry-like characteristic hidden in the hypothetic equation unifying the forage and ruminant growthl andysis equations, and (2) the breakdown of symmetry-like characteristic and corresportding resultants. The monistic breakdown of symmetry-like characteristic, which was shown by inserting either forage factors or ruminant factors into parameters, gave the cont.rastive relalionship where the autotrophic characteristic of forage RGR \{relative growth rate) and the heterotrophic characteristic of rumintant. RGR wer: derived as special cases. The dualistic breakdown of symmetry like characteristic, which was shown by inserting both forage factors and ruminant factors into parameters, gave the interconvertible relationship between forage RGR and ruminant RGR.
\end{abstract}

\section{INTRODUCTION}

In the ruminant production based on meadows or pastures, forages are not end products but are indispensable to the feeding of ruminant animals (Van Soest, 1982; Wheeler, 1987; Minson, 1990a; Humphreys, 1991). Forages and ruminants are equally important in the forage-ruminant production complex.

In our recent reports (Shimojo et al., 1998a, b, 1999) growth analysis equations of forages and those of ruminants were unified into a hypothetic equation with parameters, and then were derived again from the unified equation as special cases. Forage growth and ruminant growth might show, in a manner, two aspects of the forage-ruminant production complex (Shimojo et al., 1999). This suggests that a sort of symmetric characteristic is hidden in the unified equation and the breakdown of symmetry-like characteristic derives forage and ruminant growth analysis equations as special cases. The concept of symmetry and its breakdown is considered one of the tools to relate systematically things which seemingly look different, but we have not yet referred to this point in our previous reports (Shimojo et al., 1998a, b, 1999).

The present study was designed to investigate (1) the symmetry-like characteristic that might be expected to be hidden in the hypothetic equation unifying forage and ruminant growth analysis equations (Shimojo et al., 1998a, b, 1999), and (2) the way of its breakdown and corresponding resultants.

\footnotetext{
* Shikoku National Agricultural Experiment Station, Kagawa 765-8508

** Kyushu Liniversity Farm, Fukuoka 811-2307

**** University of the Air, Fukuoka Study Center, Fukuoka 812 -0016
} 


\section{SYMMETRY-LIKE CHARACTERISTIC AND ITS BREAKDOWN}

\section{Unifying forage and ruminant growth analysis equations and symmetry-like characteristic}

\section{(A) Reasons for unifying equations}

The main reason why RGR [relative growth rate] equation with its components for forages (Hunt, 1990) and that for ruminants (Shimojo et al., 1996, 1997) were unified into a hypothetic equation $[\mathrm{H}]$ (Shimojo $e$ al., 1998a, b) comes from the fact that both forages and ruminants grow by taking the outside energy in. In other words, the hypothetic equation was constructed in order to deal with both forages and ruminants in the analysis of energy taking in.

The simple process of unifying forage RGR and ruminant RGR is described as follows:

Forage $\mathrm{RGR}=\frac{1}{W_{F}} \cdot \frac{d W_{F}}{d t}=\left(\frac{1}{A} \cdot \frac{d W_{F}}{d l}\right) \cdot\left(\frac{A}{W_{F}}\right)$,

where $W_{F}=$ forage dry weight, $\Lambda=$ leaf area, $(1 / A) \cdot\left(d W_{F} / d t\right)=$ net assimilation rate [NAR], $A / W_{F}=$ leaf area ratio $[\mathrm{LAR}], t=$ time.

Ruminant. $\mathrm{RGR}=\frac{1}{W_{R}} \cdot \frac{d W_{R}}{d t}=\left(\frac{1}{W_{R}} \cdot \frac{d F}{d t}\right) \cdot\left(\frac{d W_{R}}{d F}\right)$,

where $W_{n}=$ ruminant body wcight, $F=$ cumulative forage intake, $\left(1 / W_{R}\right) \cdot(d F / d t)=$ forage ingestion rate per unit $W_{k}\left[\mathrm{FIRW}_{k}\right], d W_{k} / d F^{\prime}=$ feed efficiency $[\mathrm{FE}], t=$ time.

Unifying equations (1) and (2) gives the following equation as an example (Shimojo et al., 1998a, b),

$\mathrm{H}=\left(\frac{1}{\alpha} \cdot \frac{d \beta}{d t}\right) \cdot\left(\begin{array}{c}\alpha \\ W\end{array}\right) \cdot\left(\frac{d W}{d \beta}\right)$,

where $W=W_{t}$ or $W_{l t}, \alpha$ and $\beta$ are parameters, $t=$ time.

(B) Symmetry-like characteristic of the unified equation

Equation (3) was given by two procedures: (i) uniting equations (1) and (2), and (ii) replacing forage and ruminant factors with common parameters. The unified equation (3) has four features. (a) The number of terms has increased by one to three. (b) $\alpha$ and $\beta$ are exchangeable each other. (c) The choice is not made between forage and ruminant growth analyses. (d) Whichever analysis is related to $W, \alpha$ and $\beta$, RGR equation is inevitably given as follows:

$\mathrm{H}=\left(\frac{1}{\alpha} \cdot \frac{d \beta}{d t}\right) \cdot\left(\frac{\alpha}{W}\right) \cdot\left(\frac{d W}{d \beta}\right)=\frac{1}{W} \cdot \frac{d W}{d t}$.

These four features suggest that a symmetry-likc characteristic is hiddon in the unified equation (3), though this estimation seems to be inaccurate.

\section{Breakdown of symmetry-like characteristic}

What are inserted into $W, \alpha$ and $\beta$ will give the way of breakdown and corresponding resultants. The following two ways of breakdown are suggested in the present study: (i) the breakdown where either forage or ruminant factors are inserted, which is temporarily 
called monistic breakdown, (ii) the breakdown where both forage and ruminant factors are inserted, likewise called dualistic breakdown. The monistic breakdown will give a distinction between forage RGR and ruminant RGR, a sort of contrastive relationship between thern. The dualistic breakdown will give a sort of interconvertible relationship between forage and ruminant RGRs. These two relationships will be described in the following two sections, respectively.

\section{Monistic breakdown of symmetry-like characteristic and contrastive relationships}

(A) Monistic breakdown of symmetry-like characteristic

The monistic breakdown of symmetry-like characteristic is given by inserting only forage factors or only ruminant factors into $W, \alpha$ and $\beta$ of equation (3). This was already shown in our previous papers (Shimojo et al., 1998a, b), where detailed descriptions of contrastive relationships were not shown. There are two monistic breakdowns: one is the breakdown into forage RGR and the other is the breakdown into ruminant RGR.

(B) Monistic breakdown inlo forage $R G R$

In equation (3) $\alpha=A$ and $\beta=W=W_{F}$, then there occurs the monistic breakdown into forage $\mathrm{RGR}\left[\mathrm{H}_{\mathrm{F}}\right]$ as follows:

$$
\begin{aligned}
\mathrm{H}_{\mathrm{F}} & =\left(\frac{1}{A} \cdot \frac{d W_{F}}{d t}\right) \cdot\left(\frac{A}{W_{F}}\right) \cdot\left(\frac{d W_{F}}{d W_{F}}\right) \\
& =\left(\frac{1}{A} \cdot \frac{d W_{F}}{d t}\right) \cdot\left(\frac{A}{W_{F}}\right), \\
& =\frac{1}{W_{F}} \cdot \frac{d W_{F}}{d t},
\end{aligned}
$$

where $(1 / A) \cdot\left(d W_{F} / d t\right)=\mathrm{NAR}, A / W_{F}=\mathrm{LAR},\left(1 / W_{F}\right) \cdot\left(d W_{k} / d t\right)=$ forage RGR. The reduction in the number of terms occurs, from three (equation (3)) to two (equation (5)). The term, $(1 / A) \cdot\left(d W_{F} / d t\right)$, in equation (5) shows that using leaves forages synthesize, mainly from carbon dioxide, water and solar radiation, the organic matter that is used for the growth (equation (6)). The important role of leaf area in the forage growth is shown analytically by NAR and LAR in equation (5). This is a sort of analytic description of the autotrophic characteristic of the forage growth.

(C) Monistic breakdoun into ruminant $R G R$

In equation (3) $\alpha=W=W_{k}$ and $\beta=F$, then we get the other monistic breakdown, namely that into ruminant $\operatorname{RGR}\left[\mathrm{H}_{\mathrm{R}}\right]$. Thus,

$$
\begin{aligned}
\mathrm{H}_{\mathrm{i}} & =\left(\frac{1}{W_{R}} \cdot \frac{d F}{d t}\right) \cdot\left(\frac{W_{R}}{W_{R}}\right) \cdot\left(\frac{d W_{R}}{d F}\right) \\
& =\left(\frac{1}{W_{R}} \cdot \frac{d F}{d t}\right) \cdot\left(\frac{d W_{R}}{d F}\right), \\
& =\frac{1}{W_{R}} \cdot \frac{d W_{R}}{d t},
\end{aligned}
$$

where $\left(1 / W_{k}\right) \cdot(d F / d t)=\mathrm{FIRW}_{\mathrm{R}}, d W_{R} / d F=\mathrm{FE},\left(1 / W_{R}\right) \cdot\left(d W_{R} / d t\right)=$ ruminant RGR. The number of terms decreased from three (equation (3)) to two (equation (7)). The term, $\left(1 / W_{k}\right) \cdot(d F / d l)$, in equation (7) shows that ruminants have to ingest forage organic 
matter for the growth (equation (8)). The important role of forage intake in the ruminant growth is shown analytically by FIRW $\mathrm{F}$ and FE in equation (7). This is a sort of analytic description of the heterotrophic characteristic of the ruminant growth.

(D) Contrastive relationships

The reduction in the number of terms from three to two is associated with the monistic breakdown. The atutotrophic characteristic of forage RGR (equation (5)) is in contrast to the heterotrophic characteristic of ruminant RGR (equation (7)). It is suggested that the contrastive relationship in the way of taking the outside energy in for growth results from the monistic breakdown of symmetry-like characteristic hidden in the hypothetic equation unifying forage and ruminant RGRs.

\section{Dualistic breakdown of symmetry-like characteristic and interconvertible relationships}

(A) Dualistic breakdown of symmetry-like characteristic

We take up the dualistic breakdown that will suggest an interconvertible relationship between forage RGR and ruminant RGR. This is given by inserting both forage and ruminant factors into $W, \alpha$ and $\beta$ of equation (3). There are two dualistic breakdowns: onc is the conversion of forage RGR into ruminant RGR and the other is the conversion of ruminant RGR into forage RGR.

(B) Conversion of forage $R G R$ into ruminant $R G R$

In equation (3) $\alpha=\beta=W_{F}$ and $W=W_{k}$, then there occurs the dualistic breakdown into the following equation that is a mixture of forage and ruminant growth analyses $\left[\mathrm{H}_{F-R}\right]$. Thus,

$\mathrm{H}_{\mathrm{F}-\mathrm{R}}=\left(\frac{1}{W_{F}} \cdot \frac{d W_{F}}{d t}\right) \cdot\left(\frac{W_{F}}{W_{R}}\right) \cdot\left(\frac{d W_{R}}{d W_{F}}\right)$.

There is no reduction in the number of terms, namely three for both equations (3) and (9). The form of equation (9) is changed as follows to get mean $\mathrm{H}_{\mathrm{F}}$ over the interval $t_{\text {: }}$ to $t_{i}[\overline{\mathrm{H}}: \mathrm{R}]$. Thus,

$\overline{\mathrm{H}_{\mathrm{F}-\mathrm{R}}}=\left(\frac{\log _{e} W_{F 2}-\log _{e} W_{F 1}}{t_{2}-t_{1}}\right) \cdot\left(\frac{W_{F 2}-W_{F^{\prime} 1}}{\log _{n} W_{F^{2} 2}-\log _{\mathrm{r}} W_{F^{\prime} 1}} \frac{\log _{\mathrm{e}} W_{R 2}-\log _{\mathrm{e}} W_{R 1}}{W_{R^{2} 2}-W_{R 1}}\right) \cdot\left(\frac{W_{R 2}-W_{R 1}}{W_{F 2}-W_{F 1}}\right)$.

The essential point of equation (10) is that $\left(W_{k 2}-W_{p_{1}}\right)$ is regarded as not only the harvested forage weight but also the cumulative forage intake by ruminants on condition that there is a complete consumption of the harvested forage. The first parenthesis in the right-hand side shows mean forage RGR. The second parenthesis shows the ratio of mean $W_{F}$ to mean $W_{R}$ [ $\left(\right.$ mean $\left.W_{F}\right) /\left(\right.$ mean $\left.\left.W_{R}\right)\right]$. The third parenthesis, $\left(W_{R 2}-W_{R 1}\right) /\left(W_{R 2}\right.$ $\left.W_{*-1}\right)$, is regarded as feed efficiency [FE]. Actually, the complete ingestion of harvested forages by ruminants may occur when forages are young and immature and low in the concentration of anti-quality components. Fquation (10), therefore, suggests an issue of importance in the forage breeding and cultivation programs, particularly when tropical forages are targeted due to the lower intake (Minson, 1990b) that is generally related to lower digestibility (Minson, 1990c) and lower protein concentration (Minson, 1990d) compared with those of temperate forages. 
The right-hand side of equation (10) has a structure of multiplying mean forage RGR by the product of (mean $\left.W_{R}\right) /\left(\right.$ mean $W_{R}$ ) and $\mathrm{FE}$. This will lead to the following conversion on condition that ruminant growth period (= the period of forage feeding to ruminants) is equalized to forage growth period. Thus,

$$
\begin{aligned}
& \overline{\mathrm{II}_{\mathrm{F}-\mathrm{R}}}=\langle\text { Mean forage RGR }) \cdot\left\{\left(\frac{\operatorname{Mean} W_{F}}{\operatorname{Mean} W_{R}}\right) \cdot(\mathrm{FE})\right\} \\
& =\left(\frac{\log _{e} W_{F^{\prime 2}}-\log _{\mathrm{e}} W_{F^{\prime} 1}}{t_{2}-t_{1}}\right) \cdot\left\{\left(\frac{W_{F^{2}}-W_{F^{\prime} 1}}{\log _{\mathrm{e}} W_{F 2}-\log _{\mathrm{e}} W_{F^{\prime} 1}^{\prime}} \cdot \frac{\log _{\mathrm{e}} W_{R 2}-\log _{\mathrm{e}} W_{R 1}}{W_{R 2}-W_{R 1}}\right) \cdot\left(\frac{W_{R 2}-W_{R 1}}{W_{F^{\prime} 2}-W_{F 1}}\right)\right\} \\
& =\frac{\log _{\mathrm{c}} W_{R 2}-\log _{\mathrm{C}} W_{R 1}}{t_{2}-t_{1}}=\text { Mean ruminant RGR. }
\end{aligned}
$$

Equation (11) suggests a sort of procedure with which mean forage RGR is converted into corresponding mean ruminant $\mathrm{RGR}$, provided that forages are completely eaten by ruminants and forage growth period and ruminant growth period are equalized.

(C) Conversion of muminant $R G R$ into forage $R G R$

In equation (3) $\alpha=\beta=W_{R}$ and $W=W_{k}$, then there is the other dualistic breakdown $\left[\mathrm{H}_{\mathrm{k}-\mathrm{l}}\right]$ as follows:

$$
\mathrm{H}_{\mathrm{R}-\mathrm{F}}=\left(\frac{1}{W_{R}} \cdot \frac{d W_{R}}{d t}\right) \cdot\left(\frac{W_{R}}{W_{F^{\prime}}}\right) \cdot\left(\frac{d W_{F}}{d W_{R}}\right) .
$$

The reduction in the number of terms does not occur between equations (3) and (12). Changing the form of equation (12) gives mean $\mathrm{H}_{\mathrm{R}}$ over the interval $t_{1}$ to $t_{2}\left[\overline{\mathrm{H}_{k-\mathrm{F}}}\right]$ as follows:

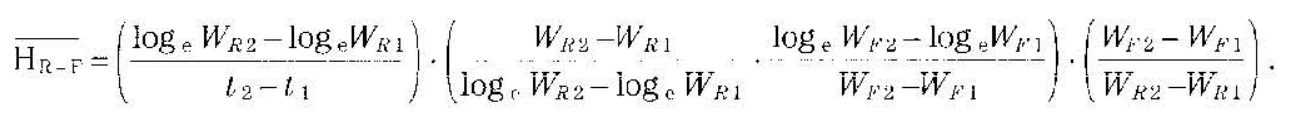

In equation (13) $\left(W_{t 2}-W_{t 1}\right)$ is regarded as the cumulative forage intake by ruminants as well as the harvested forage weight on condition that there is a complete forage consumption. The first parenthesis in the right-hand side shows mean ruminant RGR. The second parenthesis shows the ratio of mean $W_{R}$ to mean $W_{F}\left[\left(\right.\right.$ mean $\left.W_{i}\right) /\left(\right.$ mean $\left.\left.W_{F}\right)\right]$. The third parenthesis, $\left(W_{k 2}-W_{k 1}\right) /\left(W_{k z}-W_{k 1}\right)$, is regarded as feed conversion [FC].

The right-hand side of equation (13) has a structure of multiplying mean ruminant RGR by the product of (mean $W_{k}$ )/(mean $W_{i}$ ) and $\mathrm{FC}$. This will lead to the following conversion on condition that there is a complete forage consumption by ruminants and growth periods are equalized between forages and ruminants. Thus,

$$
\begin{aligned}
\overline{\mathrm{H}_{\mathrm{R}-\mathrm{F}}} & =(\text { Mean ruminant RGR }) \cdot\left\{\left(\begin{array}{l}
\text { Mean } W_{R} \\
\text { Mean } W_{F}
\end{array}\right) \cdot(\mathrm{FC})\right\} \\
& =\left(\frac{\log _{\mathrm{c}} W_{R^{2}}-\log _{\mathrm{e}} W_{k^{\prime} 1}}{t_{2}-t_{1}}\right) \cdot\left\{\left(\frac{W_{R 2}-W_{R 1}}{\log _{\mathrm{e}} W_{R 2}-\log _{\mathrm{e}} W_{R 1}} \cdot \frac{\log _{\mathrm{e}} W_{F 2}-\log _{\mathrm{e}} W_{F \mathrm{t}}}{W_{F 2}-W_{F 1}}\right) \cdot\left(\begin{array}{l}
W_{F 2}-W_{F 1} \\
W_{R 2}-W_{R^{1}}
\end{array}\right)\right. \\
& =\frac{\log _{\mathrm{e}} W_{F 2}-\log _{\mathrm{e}} W_{F 1}}{t_{2}-t_{1}}=\text { Mean forage RGR. }
\end{aligned}
$$


Equation (14) shows a sort of procedure for converting mean ruminant RGR into corresponding mean forage RGR, provided that ruminant growth period and forage growth period are equalized and ruminants eat forages completely.

(D) Interconvertible relationships

No reduction in the number of terms is associated with the dualistic breakdown. Forage RGR and ruminant RGR are related equivalently on condition that there is a complete consumption of harvested forages by ruminants and growth periods are equalized between forages and ruminants. The dualistic breakdown has two issues that should be discussed. (1) Forage RGR and ruminant RGR are forcedly related, but this will lead to the necessity of breeding forages that can be completely eaten by ruminants, an issue of great importance in ruminant agriculture. (2) In actual cases the forced equalization of growth periods between forages and ruminants will lead to a segmental treatment of ruminant growth period, because growth period is usually longer for ruminants than for harvested forages. However, this may give an image of the increase in meadow area with the growth of or the increase in the number of ruminants, when the forage harvested at once from the meadow is being fed to ruminants. The interconvertibility is associated with a sort of equivalent status between forage and ruminant production.

It is suggested that the interconvertible relationship between forage RGR and ruminant RGR results from the dualistic breakdown of symmetry-like characteristic: hidden in the hypothetic equation unifying forage and ruminant RGRs.

\section{Suggestions from the present analyses}

The forage growth and the ruminant growth are different things, because forages are autotrophic and ruminants are heterotrophic. On one hand this emphasizes the distinction between them; on the other hand, the close relationship is formed due to the important role of forages as a major source of ruminant feeds.

This distinction and the close relationship are described systematically by the two ways of breakdown of symmetry-like characteristic hidden in the hypothetic equation that unifies forage and ruminant growth analysis equations: namely (1) the monistic breakdown suggesting the autotrophic characteristic of forage growth analysis and the heterotrophic characteristic of ruminant growth analysis, and (2) the dualistic breakdown suggesting the equivalent status between forage RGR and ruminant RGR through the interconvertible relationship between them. The present analyses might give a sort of unified viewpoint to the forage-ruminant production complex, but require further investigation.

\section{REFERENCES}

Humphreys, L. R. 1991 Introduction. In "Tropical pasture utilisation", Cambridge Lniversity Press, Cambridge, U. K., pp. 1-5

Hunt, R. 1990 Basic Growth Analysis. Unwin Hyman Lud., London, U. K.

Minson, D. J. 1990a Ruminant production and forage nutrients. In "Forage in Ruminant Nutrition", Academic Press, Inc., San Diego, pp. 1-8

Minson, D. J. $1990 \mathrm{~b}$ Intake of forage by housed ruminants. In "Forage in Ruminant Nutrition" Academic Press, Inc. San Diego, pp. 9-59

Minson, D. J. 1990c Digestible energy of forage. In "Forage in Ruminant Nutrition", Academic Press, 
Inc., San Tiego, pp. 85-149

Minson, 1) .I. 1990d Protein. Im "Forage in Ruminant Nutrition", Academic Press, Inc., Sar Diego, pp. 162-207

Shimojo, M., Y. Masuda, Y. Imura, M. Tobisa aud I. Goto 1996 A simple analysis of the relationship between feeding and growth in beef cattle. In "Rumen microorganisms, digestion and productivity in ruminants", Proc. Satell. Symp. 8th Anim. Sci. Congr. AAAP, P-08

Shimojo, M., T. Bungo, Y. Imura, M. Tobisa, N. Koga, Y. Nakano, I. Goto and Y. Masuda 1997 Relative growth rate of beef cattle expressed using factors rclated to feed intake, maintenance requirements and fced efficiency. J. Fac. Agr., Kyushu Univ., 42: 87-93

Shimojo, M., T. Bungo, N. Koga, Y. Inuurd, M. Tobisa, S. Tao, M. Yunus, Y. Nakano, l. Goto, M. Furuse and Y. Masuda 1998a An equation with a potential for describing relative growth rate of forages and of ruminants using related component factors. Proc. 8 th World Conf. Anim. Prod., Seoul, Korea, Vol. II $510-511$

Shimojo, M., T. Bungo, M. Tobisa, Y. Imura, N. Koga, S. Tao, M. Yunus, Y. Nakano, 1. Goto, M. Furuse and Y. Masuda 1998b A hypothetic equation from which growth analysis equations of forages and ruminants are derived as special cases. I. Fac. Agr., Kyustu liniw. 43: 103-109

Shimojo, M., T. Bungo, Y. Imura, M. Tobisa, N. Koga, S. Tao, M. Yunus, Y. Nakano, I. Golo, M. Furuse and Y. Masuda 1999 Two different-type equations of relative growth analysis for both forages and ruminants and deriving of them from a hypothetic equation. J. Fac. Agr, Kyushu Univ., 43: 355-364

Van Soest, P. J. 1982 Nutritional quality. In "Nutritional Ecology of the Ruminant": Cornell University Press, New York, pp. 23-74

Wheeler, I. L. 1987 Pastures and pasture rosearch in southerr Australia. In "Femperate Pastures their production, use and Inlandgement - ", cod. by J. L. Wheeler, C. J. Pearson and G. E. Robards, Australian Wool Corporation/CSIRO, Australia, pp. 3-31 